Jasmina D. Moskovljević Popović*

УДК 811.163.41'367.635

Univerzitet u Beogradu

ДОИ https://doi.org/10.18485/analiff.2017.29.2.7

Filološki fakultet**

\title{
O KORELATIVNIM KONSTRUKCIJAMA U JUŽNOSLOVENSKOJ LINGVISTICI (II)
}

\begin{abstract}
Ovaj rad predstavlja drugi deo kritičkog pregleda opisa i analize korelativnih konstrukcija u južnoslovenskoj lingvistici. Uz kratak osvrt na Belićevo (u odnosu na druge sintaksičare po mnogo čemu različito) shvatanje ovog problema, u radu se izlažu i analiziraju gledišta autora novijih gramatika srpskog i hrvatskog jezika nastalih krajem prošlog i početkom ovog veka.
\end{abstract}

Ključne reči: složena rečenica, zavisna klauza, korelativne konstrukcije, novije gramatike srpskog jezika i hrvatskog jezika

\section{Uvod}

Prvi deo pregleda istraživanja korelacije, korelativnih veznika i korelativnih konstrukcija u južnoslovenskoj lingvistici s kraja 19. i tokom 20. veka pokazao je u kolikoj meri su korelativne konstrukcije stalno prisutan, ali istovremeno i nedovoljno jasno određen, ispitan, a još manje razjašnjen problem (Moskovljević Popović 2016). Kada je reč o statusu rečenica s korelativnom konstrukcijom, uočljivo je da se izdvajaju dva međusobno suprotstavljena stava - onaj po kome se sve ovakve rečenice svrstavaju u relativne rečenice (Musić 1899, delimično i Stevanović 1979) ${ }^{1}$ i onaj po kome se problem korelacije svodi samo na dodatnu upotrebu još jednog elementa u strukturi rečenice pri čemu se njen kategorijalni status,

* $\quad$ Katedra za opštu lingvistiku, Filološki fakultet, Studentski trg 3, 11000 Beograd, jasmina.moskovljevic@fil.bg.ac.rs.

** Ovaj rad je nastao u okviru projekta „Standardni srpski jezik: sintaksička, semantička i pragmatička istraživanja“" (178004), koji finansira Ministarstvo prosvete i nauke Republike Srbije

1 U Stevanovićevoj klasifikaciji izuzetak predstavljaju pogodbene i dopusne rečenice, v. Moskovljević Popović (ibid.) 
odnosno pripadnost određenoj vrsti zavisnih rečenica ne menja (Maretić 1899/1963, Novaković 1902, Lalević 1951). Pri tome ni jedna ni druga grupa autora ni u jednom trenutku ne dovodi u pitanje aksiomatski i opšte prihvaćen postulat da je reč o zavisnosloženim rečenicama.

Aleksandar Belić, međutim, zastupa jedno drugačije gledište. U radu o pravilnoj upotrebi zapete, on se dotiče i analize korelativnih konstrukcija i navodi: „Iznoseći slučajeve sa inverzijom ja sam rekao da se takve rečenice osećaju gotovo kao naporedne sa glavnom rečenicom; ali ima dosta slučajeva gde se one zaista razvijaju u „saodnosne“ ili korelativne rečenice kod kojih je često teško reći koja je rečenica glavna, a koja sporedna, toliko su one stilizovane. U rečenici Kakva mati, takva kći nesumnjivo smo prvobitno u mišljenju imali Kći je onakva kakva je mati, inverzijom i pretvaranjem onakva u takva, a moglo je ostati i onakva, dobili smo dve potpuno naporedne rečenice: Kakva (je) mati, takva (je) kći. Korelativna zamenica ili prilog taj, onaj, tad i slično često se podrazumeva, pa ipak i takve rečenice treba smatrati kao korelativne. Napr.: Kad srce zapišti, misao je kriva. Ovde je Rakić sigurno zamišljao tad. Ili: Ko mnogo pita, rado ne daje — očigledno taj rado ne daje. Ili: „Ko ovoga kamena ponese, kajaće se; a ko ne ponese, kajaće se“ — u oba slučaja taj će se kajati $\mathrm{i}$ sl. (Belić 1949: 18-19). U ovom kratkom odlomku u raspravi posvećenoj potpuno drugoj temi Belić iznosi i dve tvrdnje od izuzetnog značaja za anlizu korelativnih konstrukcija: 1. da uz obeležja zavisnih, ovakve rečenice poseduju i neka obeležja naporednih konstrukcija; 2. da se i u rečenicama u kojima korelativ nije eksplicitno izrečen, on podrazumeva. Da je Belić zbilja smatrao da korelativne konstrukcije imaju poseban, specijalan kategorijalni status koji ih svrstava negde između naporedno i zavisnosloženih rečenica potvrđuje i njegova tvrdnja s kraja navedene rasprave: „Od potpune podvojenosti preko poluzavisnosti (inverzije, korelativnosti) ${ }^{2}$ i još nečega što je i od toga manje ... do pune zavisnosti ima, kao što smo videli, ceo niz slučajeva među kojima, svakako, i prelaznih stupnjeva... (ibid.: 23).

Belić je na ovaj način u južnoslovenskoj lingvistici otvorio pitanje koje dotad nije bilo razmatrano - pitanje o kategorijalnom statusu rečenica s korelativnom konstrukcijom, kao i šire pitanje o tipologiji složenih rečenica uopšte i (skalarnoj) prirodi kontinuuma nezavisne - zavisne rečenice.

2 Podvukla JMP. 


\section{O korelativnim konstrukcijama u novijim južnoslovenskim gramatikama}

2.1. U Gramatici srpskog jezika za gimnazije i srednje škole korelativi zavisnih rečenica razmatraju se, definišu i opisuju u delu Sintaksa (Popović 122010). U posebno izdvojenom odeljku posvećenom korelativima zavisnih rečenica navodi se da se ,veza više jedinice i zavisne rečenice može ... pojačati i istaknuti (fakultativnom) upotrebom tzv. korelativa, tj. pokaznih zamenica i priloga koji odgovaraju značenju i funkciji zavisne rečenice“" (ibid: 311). U posebnu grupu, kao srodne sa korelativima, ali donekle i različite od njih, izdvajaju se lične zamenice kojima se supstituiše prethodno izdvojena zavisna klauza sa imeničkom funkcijom (npr.: Ko drugome jamu kopa, taj/on u nju pada), kao i imenički upotrebljena pokazna zamenica u jednini srednjeg roda kojom se upućuje na izričnu rečenicu ${ }^{3}$ (Diskutovali su o tome da li je Marko zaslužio nagradu). Ovim jedinicama se više implicitno nego eksplicitno pripisuje poseban status. Takođe se ističe da je upotreba korelativa zavisnih rečenica ,naročito važna tamo gde se njihovim padežnim oblikom (i upotrebom predloga) precizira uloga sadržaja zavisne rečenice u višoj konstrukciji“" (ibid.: 312).

Korelativi i korelativne konstrukcije potom se razmatraju tokom opisivanja i prikazivanja strukture pojedinih tipova zavisnih klauza. Izdvaja se jedanaest različitih vrsta zavisnih klauza: izrične, odnosne imeničkog tipa, odnosne pridevskog tipa, mesne, vremenske, uzročne, uslovne, dopusne, namerne, posledične i poredbene. Za pojedine od izdvojenih vrsta (izrične, odnosne, mesne, dopusne, poredbene i posledične) navode se, nekad eksplicitno, nabrajanjem, a nekad implicitno, navođenjem odgovarajućih primera, korespondentni korelativi. Za druge vrste zavisnih rečenica korelativi se ne navode.

Pri opisu izričnih rečenica ukazuje se da se ,izrične rečenice često ne vezuju direktno za reč koju dopunjavaju, nego preko korelativne poimeničene pokazne zamenice“ (ibid.: 313), kao, na primer, Ivan se pomirio s tim da neće ići na letovanje. Kad je o korelativima odnosnih rečenica pridevskog tipa reč, uočava se njihov značaj za razlikovanje atributske i apozitivne funkcije odnosnih rečenica - korelativ se može pojaviti samo uz odnosne klauze sa atributskom funkcijom (up. Podigao je onu ruku u kojoj

3 Za više, v. Ivić (1983) i Ružić (2008). 
je držao telegram : *Podigao je onu desnu ruku, u kojoj je držao telegram (ibid.:320). Kako se razlikuju tri tipa veze relativne rečenice i imeničkog pojma na koji se ona odnosi, ukazuje se i na tri korespondentna tipa korelativa: 1. ako se rečnica odnosi na identitet imeničkog pojma, onda se prema zamenici koji javlja korelativ onaj, 2. ako se rečenica odnosi na karakteristike pojma, onda se kao korelativ zamenice kakav upotrebljava zamenica onakav, 3. ako se odnosnom rečenicom ukazuje na obim ili dimenzije pojma, onda se prema zamenici koliki u upravnoj klauzi javlja korelativ onoliki. Takođe, ako u odnosnoj rečenici relativizator ima mesno ili vremensko priloško značenje, onda se umesto zamenice koji može upotrebiti odgovarajući odnosni prilog s mesnim (gde) ili vremenskim značenjem $(\mathrm{kad})$, ali se pri tome korelativ u upravnoj klauzi ne menja: To je onaj hotel gde smo odseli; To je bilo onog dana kad smo išli na izlet (ibid.: 319-320). Korelativ u svim navedenim primerima odnosnih rečenica ima funkciju korelativnog atributa. Kako Lj. Popović dalje navodi, za razliku od odnosnih rečenica pridevskog tipa, u odnosnim rečenicama imeničkog tipa kao korelativi se upotrebljavaju lične zamenice ili poimeničene pokazne zamenice (naspram imeničke odnosne zamenice $k o$ ), ili poimeničena pokazna zamenica u jednini srednjeg roda to (naspram imeničke odnosne zamenice što): Ko rano rani, on/taj dve sreće grabi; Što možeš da uradiš danas, to ne ostavljaj za sutra (ibid.: 322).

Kad je o složenim rečenicama sa zavisnom klauzom adverbijalnog tipa reč, Lj. Popović izdvaja korelative koji se javljaju u rečenicama sa mesnom, dopusnom, poredbenom i konsekutivnom klauzom. Razmatrajući mesne rečenice, on navodi da se naspram odnosno-upitnih priloga za mesto (gde, kuda, kamo, odakle) javljaju priloški korelativi tu, tamo, tuda i sl.: Gde on udari, tu trava ne raste; Prešao je tamo odakle je imao bolji pogled na igralište (ibid.:323). U delu teksta gramatike posvećenom dopusnim rečenicama ističe se da se ,iza dopusne rečenice može (se) upotrebiti kohezivna rečca ipak, kojom se (slično korelativnim zamenicama i prilozima) ističe smisaona veza više i dopusne rečenice“" (ibid.: 331). Kada je o poredbenim rečenicama za jednakost reč, Popović navodi da se prema veznicima kao što, kao da, koliko i sl. u upravnoj rečenici mogu javiti različiti korelativi: onako, tako, isto tako, onoliko - Postupio je onako kao što mu je bilo rečeno (ibid.: 334). A u složenoj rečenici sa posledičnom klauzom „u višoj rečenici obično postoje korelativni pokazni prilozi tako ili tol- 
iko ili korelativne pokazne zamenice takav ili toliki, koji pokazuju koja se komponenta situacije karakteriše i time uvode posledičnu rečenicu" (ibid.: 335). Pri opisu ostalih tipova rečenica sa adverbijalnom klauzom (vremenskih, uzročnih, kondicionalnih i namernih) korelativi se ne spominju. ${ }^{4}$

Popović je prvi sintaksičar koji je ukazao da kategorija korelativnih reči ne sačinjava jedinstven skup, te da je korelative zavisnih rečenica sa imeničkom funkcijom, kao i imenički upotrebljenu pokaznu zamenicu u jednini srednjeg roda kojom se upućuje na izričnu rečenicu potrebno posebno izdvojiti i analizirati. On je takođe na drugačiji način odredio status i funkciju sintaksičkog konstituenta ipak u upravnoj klauzi složene rečenice sa dopusnom klauzom - dok su ovu leksemu raniji gramatičari (a i leksikografi) ${ }^{5}$ svrstavali među korelativne reči, Popović govori o ,kohezivnoj rečci ipak“".

2.2. Korelativima i korelativnim konstrukcijama bavi se i Gramatika hrvatskoga jezika za gimnazije i visoka učilišta J. Silića i I. Pranjkovića (2007). U ovoj Gramatici osnovna podela zavisnosloženih rečenica vrši se prema sintaksičkoj funkciji koju zavisne klauze imaju u strukturi složene rečenice. Po ovom kriterijumu sve eksplicitne zavisnosložene rečenice dele se na predikatske, subjekatske, objekatske, atributske i adverbijalne (ibid.: 329-330).

Za složene rečenice sa predikatskom klauzom navodi se da se u njima mogu javiti ,i suodnosne ili korelativne riječi (zamjenice ili pridjevi), npr. On je onaj koji jest, Ni ljeta nisu ono što su nekad bila, Kuća mu je takva da je nema u okolici“" (ibid.: 330). Subjekatske rečenice, koje se u predloženoj klasifikaciji dele na odnosne, zavisnoupitne i izrične, takođe mogu u strukturi upravne klauze imati korespondentni korelativ. Odnosne rečenice sa subjekatskom funkcijom, ,slične su predikatnima po tome što omogućavaju uvrštavanje pokazne zamenice ili zamjeničkoga priloga koji se sa supstitutivnim veznim sredstvima 6 nalazi u korelativnome odnosu“" (ibid.: 331). Kao ilustracija za ovu vrstu konstrukcija navode se sledeće

$4 \quad$ V., međutim, Popović (1977: 160 i dalje). U ovom radu se ne samo izdvajaju korelativi namernih klauza (zato, radi toga), već se objašnjava i ne(mogućnost) njihove upotrebe u različitim tipovima složenih rečenica sa finalnom i pseudofinalnom klauzom.

5 V. odrednicu ,ipak“ u Rečniku MS i Rečniku SANU.

6 Podvukla JMP. Iz navedene definicije nije jasno šta se podrazumeva pod „supstitutivnim veznim sredstvima“. 
rečenice: (Onaj) tko ne zna, neka pita ili Tko ne zna, (onaj) neka pita; (Oni) koji su pitali, znaju ili Koji su pitali, (oni) znaju. ${ }^{7}$ Silić i Pranjković ne navode korelative za preostale dve vrste rečenica sa subjekatskom funkcijom koje izdvajaju (zavisnoupitne i izrične subjekatske rečenice) mada bi i njih, naravno, bilo moguće navesti (npr.: To kako je teško pisati udžbenik, dobro je poznato). Slično je i sa objekatskim rečenicama. I one su u ovoj klasifikaciji, kao i subjekatske, podeljene na odnosne, zavisnoupitne i izrične. Korelativi se pominju samo prilikom razmatranja odnosnih objekatskih rečenica za koje se tvrdi da se ,i u takve rečenice mogu uvrstiti suodnosne riječi, a kao vezna sredstva služe relativizatori (tj. odnosne zamjenice i pridjevi)“ (ibid.:332). Ova tvrdnja ilustruje se sledećim primerima: Pitajte (onoga) koga sretnete; Pozvao sam (one) koje si predložio; Jeste li našli (ono) što ste tražili i Kupit ću (onakvu) kakvu nađem. Iako se upotrebom zagrada u svim primerima (ispravno) ukazuje na fakultativnost korelativnog konstituenta, ne navode se oni drugi u kojima je upotreba korelativa u strukturi upravne klauze obligatorna.

Kada je o zavisnim rečenicama sa adverbijalnom funkcijom reč, Silić i Pranjković razlikuju mesne, vremenske, načinske, poredbene, uzročne, namerne, kondicionalne, posledične i dopusne rečenice. O mesnim (lokalnim) rečenicama kažu da ,mogu u zavisnosloženu rečenicu biti uvrštene na dva načina: ili izravno po predikatu osnovne surečenice, npr. Neka sjedne gdje hoće, ili po mjesnom zamjeničkom prilogu, npr. Naći ćete ih ondje gdje ste ih $i$ ostavili. U drugome slučaju riječ je o suodnosnim (korelativnim) mjesnim rečenicama u kojima vezna sredstva ekspliciraju sadržaj mjesnih zamjeničkih priloga" (ibid.: 335). Dalje se navode primeri rečenica u kojima se kao korelativi mesnih klauza javljaju zamenički prilozi ovde, tamo, onde, onamo, ovuda, onuda, odatle, donde i dotle. U delu teksta o vremenskim rečenicama korelativi se ne spominju. Pri razmatranju načinskih rečenica, navodi se da načinske rečenice $s$ veznikom kako mogu biti i korelativnog tipa. Tada je u upravnoj rečenici moguća upotreba načinskih zameničkih priloga ovako, tako i onako, kao u rečenicama: Postupi ovako kako ti kažem; Ne radi se tako kako biste vi

7 Među primere su, očito greškom, uvrštene i rečenice ( $\underline{\text { Ono }})$ što ne znate, pitajte i Što ne znate, (ono) pitajte u kojima se zavisne klauze ne nalaze u funkciji subjekta već direktnog objekta. Pogrešno je klasifikovan i naredni primer sa veznikom kako i korelativom onako (ibid.:331) u kome zavisna klauza takođe ne vrši subjekatsku funkciju. 
htjeli, Uradili smo onako kako je najbolje (ibid.: 340). Poredbene (komparativne) rečenice Silić i Pranjković dele u tri grupe: rečenice u kojima se vrši poređenje po jednakosti, rečenice u kojima se vrši poređenje po nejednakosti i raščlanjene poredbene rečenice (rečenice korespondencije). O korelativima govore samo pri analizi treće, poslednje grupe poredbenih rečenica za koje kažu da „u njima dolaze veznici što, kako i koliko, a često i suodnosne zamjeničke riječi to, tako i toliko (ibid.: 341). Zatim navode primere među kojima su i Što smo išli dalje, to je postajalo sve mračnije; Kako smo se približavali cilju, tako je nestajalo umora; Koliko su uživali $u$ vožnji do otoka, toliko su se $i$ bojali valova. Za složene rečenice sa uzročnom klauzom ovi autori tvrde da im nisu svojstvene korelativne reči i izrazi, te da je u ovo tipu rečenica njihova upotreba neobična i stilski obeležena (ibid.: 342). Nasuprot tome, za rečenice sa konsekutivnom klauzom navode da su u njima korelativne reči česte, da imaju ,pojačajnu ulogu“ i da se u ovom tipu rečenica u ovoj funkciji najčešće upotrebljavaju zamenički prilozi tako i toliko (ibid.: 342). U delu teksta o namernim klauzama Silić i Pranjković naglašavaju da se namerne rečenice ,razlikuju od ostalih zavisnosloženih rečenica ... i po tome što u njima ne dolaze niti mogu dolaziti suodnosne riječi zameničkog tipa. Nije npr. ovjereno *Otišli su u šumu tako da naberu gljiva ili sl. (ibid.: 346). Čini se da je ovako formulisana napomena suvišna ako se ima u vidu osnovna funkcija, a i značenje namernih klauza. Kako je reč o odredbama/dopunama cilja, razumljivo je da se u upravnoj klauzi ne može naći korelativ tipa „tako“ i sl., ali je potpuno gramatična upotreba korelativa zato ili radi toga: Otišli su u šumu zato da naberu pečurke. Korelativi i korelativne konstrukcije ne spominju se kad se analiziraju pogodbene (kondicionalne) rečenice. A uz dopusne rečenice govori se o „suodnosnim česticama“ ipak (Iako je umoran, ipak je došao), opet (Ako je i malo, opet dobro dođe) i ali (Ako i izgleda ružno, ali je ukusno) (ibid.: 349-350).

Prilikom razmatranja zavisnih rečenica sa atributskom funkcijom, Silić i Pranjković ne pominju upotrebu korelativa u odnosnim rečenicama sa relativizatorima koji, čiji, kakav i koliki. Oni u ovom segmentu teksta navode i rečenice tipa Dat ćemo to onome tko se prvi javi, Pozdravite svakoga koga vidite i sl., ali naglašavaju da se takve rečenice ne analiziraju kao atributske, već kao subjekatske ili objekatske (ibid.: 352). Isto važi i za rečenice sa imeničkom odnosnom zamenicom što koja je nekomuta- 
bilna sa zamenicom koji (Priča ono što mu padne na pamet; Dogodilo se ono čega smo se bojali i sl.) - i rečenice ovog tipa ne analiziraju se kao atributske već kao „ponajprije subjektne ili objektne“ (ibid.: 354).

Analizu korelativa i korelativnih konstrukcija u Gramatici Silića i Pranjkovića odlikuje izvestan stepen neodređenosti i nedorečenosti. Ovaj tip veze između upravne i zavisne klauze nigde se eksplicitno ne definiše, niti se diskutuje o njegovoj prirodi i strukturnim i funkcionalnim razlikama između složenih rečenica s korelativima i onih bez njih. Takođe ostaje nejasno i nerazjašnjeno zašto se o korelativima govori samo uz pojedine tipove zavisnih klauza dok se uz druge oni uopšte ne spominju.

\section{Završna razmatranja}

Čak i letimično poređenje prikaza i analize korelativnih konstrukcija koje vrši Popović s jedne, i Silić i Pranjković s druge strane, ukazuje na postojanje nemalih razlika. Uz osnovnu, koja se odnosi na primarni kriterijum prema kome se zavisne rečenice dele, uočavaju se i druge koje se tiču kako razlika u obimu i sadržaju skupa jezičkih jedinica koje se ubrajaju u korelative, tako i razlika koje se odnose na to u kojim se sve tipovima zavisnih rečenica korelativne konstrukcije registruju i opisuju. Tako, na primer, govoreći o poredbenim rečenicama za jednakost, Popović navodi da se prema veznicima kao što, kao da, koliko i sl. u upravnoj rečenici mogu javiti korelativi onako, tako, isto tako, onoliko, dok Silić i Pranjković uopšte ne pominju upotrebu korelativa u ovom tipu rečenica. Isto se odnosi i na odnosne rečenice u atributskoj upotrebi.

Shodno prvenstvenoj nameni i svrsi analiziranih gramatika (udžbenici za srednje škole, mada obe, kako u svojim sredinama, tako i na širem južnoslovenskom prostoru imaju mnogo dalekosežniji značaj i uticaj), korelativima i korelativnim konstrukcijama ni u jednoj od njih nije posvećeno puno prostora, što je i razumljivo kada se imaju u vidu ograničenja koja važe za ovaj tip tekstova. Zato se o stavovima njihovih autora o teorijskom statusu, mestu i funkciji korelativa u strukturi zavisnosložene rečenice može zaključivati pre posredno, preko izdvojenih kategorija korelativa i navedenih primera, nego direktno, analizom eksplicitno izloženih tvrdnji i argumenata kojima se one potkrepljuju. Međutim, 
čak i nepotpuno navođenje skupova jezičkih jedinica koje se mogu pojaviti kao korelativi pojedinih tipova zavisnih klauza, uz istovremeno ukazivanje na specifičnosti njihove realizacije i unutarrečenične funkcije, omogućava bolji uvid u prirodu ovog fenomena. Isto tako, sistemska zastupljenost primera s korelativima prilikom opisa pojedinih vrsta rečenica, ali i njihovo odsustvo pri opisu drugih, dopušta formiranje jasnije predstave o granicama prostiranja ovog rečeničnog podsistema i ukupnom obimu klase konstrukcija koje su u njega uključene.

S druge strane, utvrđivanje teorijskog statusa, precizne funkcije i odnosa podsistema rečenica s korelativima prema drugim rečeničnim (pod)sistemima ostaje i dalje otvorena tema za buduća istraživanja i nove, opsežnije i dublje analize.

\section{Literatura:}

Belić, A. (1950). O stavljanju zapete. Naš jezik, knj. I n.s., sv. 1-2, 7-23.

Ivić, M. (1983). Lingvistički ogledi. Beograd: Prosveta,

Moskovljević Popović, J. (2016). O korelativnim konstrukcijama u južnoslovenskoj lingvistici (I). Anali Filološkog fakulteta XXVIII/1, 337-346.

Popović, Lj. (1977). Namerne rečenice u funkciji naporednih. Književnost i jezik XXIV/1-4, 154-163.

Popović, Lj. (122010). Sintaksa. U: Ž. Stanojčić i Lj. Popović, Gramatika srpskog jezika za gimnazije i srednje škole. Beograd: Zavod za udžbenike i nastavna sredstva, 204-384.

Rečnik srpskohrvatskog književnog i narodnog jezika, knj. 7. Beograd: SANU i Institut za srpski jezik.

Rečnik srpskohrvatskoga književnog jezika, knj. 2. Novi Sad-Zagreb: Matica srpska-Matica hrvatska, knj. 4-6, Novi Sad: Matica srpska, 1967.

Ružić, V. (2008). Jedan vid gramatikalizacije rečeničnog značenja. Južnoslovenski filolog LXIV, 419-435. 
Jasmina D. Moskovljević Popović

\section{Jasmina Moskovljević Popović}

\section{Summary}

\section{ON CORRELATIVE CONSTRUCITONS IN SOUTH-SLAVIC LINGUISTICS (II)}

The paper presents the second part of a critical review of the description and the analysis of correlative constructions in South-Slavic linguistics. At the beginning, a brief overview of Belić's understanding of the problem, which differs from those of other syntacticians, is introduced. In the second part of the paper, the standpoint on correlative constructions of the authors of contemporary grammars of the Serbian language and of the Croatian language is presented, examined and discussed. 